\title{
Determination of organophosphorus insecticide residues in the rice paddies
}

\author{
${ }^{1}$ R. Arjmandi; ${ }^{1 *}$ M. Tavakol; ${ }^{2}$ M. Shayeghi \\ ${ }^{1}$ Department of Environmental Engineering, Graduate School of Environment and Energy, Science and Research \\ Branch, Islamic Azad University, Tehran, Iran \\ ${ }^{2}$ School of Public Health and Institute of Public Health Research, Tehran University of Medical Science, \\ Tehran, Iran \\ Received 27 October 2008; $\quad$ revised 1 August 2009; accepted 28 October 2009
}

\begin{abstract}
In most rice paddies in Mazandaran Province, diazinon is applied to control Chilo suppressalis. Due to the extensive application of insecticides in the rice paddies of the Caspian coasts of Iran, this investigation was carried out on the rice fields in order to obtain the necessary data and information on the concentration of insecticide residues. A total of 125 samples were taken from five areas of Amol township in 2007. Then, according to the analysis of variance procedures, the water samples were statistically analyzed after the spraying of diazinon. Results indicate that the insecticide was used frequently to control stem boring caterpillar of rice. The residuals of this toxic chemical were observed in the majority of stations from the day after the spraying until one to two months later. The greatest level of diazinon was observed in station 1 in amount of $1.14 \mathrm{ppm}$. This study revealed that the physical and chemical properties of the studied diazinon such as fumigation characteristic as well as the ecological conditions and soil type influence the reduction and eventual removal of the insecticides during the cultivation and harvest periods.
\end{abstract}

Keywords: Insecticide; Rice; Sampling; Statistical methods; Thin layer chromatography

\section{INTRODUCTION}

Environmental pollution is one of the serious predicaments of the modern world (Hela et al., 2005). During the last decade, due to the significant increase in the environmental pollutants and lack of precautionary measures or observance of the environmental regulations, it has become a global problem (Bondarenko et al., 2004; Hela et al., 2005; Abdel-Halim et al., 2006; Wilsont and Foos, 2006).

The ever-increasing trend of population growth and the higher rate of food consumption have forced the producers to intensify their efforts to increase food products. The farmers as one of the main components of this chain are also using escalating amounts of pesticides to protect their crops (Ckamaca, 2002; Struger, 2002). Pesticide residues in food items have been a concern to environmental and consumer groups of their wide spread use (Darko et al., 2007). Today,

*Corresponding Author Email: mitra_tavakol@yahoo.com Tel.: +989111 127 2944; Fax: +981212552782 pesticides are widely used to control insects as agricultural pests or as threats to the human health through the transfer of dangerous diseases (Ckamaca, 2002; Pedersen et al., 2006; Rawn et al., 2006). Although these chemicals facilitate the anthropogenic land use, they usually pose danger to the biotic species and seriously damage the human living environment (Sudo et al., 2002; Na et al., 2006).

These compounds have been or continue to be used in large quantities (Imo et al., 2007). The most important effects of the synthetic pesticides, especially organochlorinated and organophosphorus (OP) pesticides are water and soil pollutions, as well as the contamination of vegetables, fruits, milk, food products and other living organisms (Denistrop, 2000; Ahmad, 2001; Erin et al., 2001; Hamilton et al., 2003). Pollution of the water in the river and depleting its resources can put the lives of many people in danger (Chimwanza et al., 2006). 
Rice, as the main staple of the Iranian people, is always attacked by the various pests during cultivation and harvest. Thus, the farmers in the rice paddies of northern Iran use different pesticides to protect their crops, some of which are persistent and enter the food chain and eventually the human body. Also, it is quite possible for them to contaminate in the rice crops (Nouri et al., 2000). The phosphorous insecticides are primarily being used to combat agricultural pests in Iran. Investigations conducted in Iran indicated that some of the surface waters and the surrounding environments were contaminated with OP pesticides (Shayeghi et al., 2001; Tarahi Tabrizi, 2001). Some studies have also performed regarding the environmentally clean utilization of rice husk as an effective absorbent of easte materials (Abdel-Ghani et al., 2007; Mumin et al., 2007; Mahvi, 2008).
Chillo suppressalis is one of the primary pests damaging rice crops. OP diazinon in granule form is used to combat the above-mentioned pest. Diazinon is an insecticide with wide range of applications against various types of pests including those existing in soil (Cox,1993). However, as the Mazandaran Province with 202 thousand $\mathrm{h}$ of rice paddies is the most contaminated Province. Amongst the various groups, the organophosphorous chemicals are the most prevalent agricultural pesticides. Therefore, the impact of diazinon residues on the water and the environment of Amol township was studied in spring and summer 2007 in Mazanadaran Province (Rawn et al., 2006). A total of 125 samples were taken with the thin-layer chromatography method to determine the amount of insecticide residue at harvest time in spring and summer 2007 (Tavakol, 2007).



Fig. 1: The study area in Mazandaran Province 
In Mazandaran Province, as one of the agricultural poles of the country that consumes considerable amount of pesticides each year, the adverse consequences on the local residents can not be overlooked. Thus, in order to preserve the well being and health of the biotic species, the initial step is to determine the residues of such toxic chemicals in the environment (Shayeghi et al., 2001). The study has been conducted in Amol; north of Iran, in 2008.

\section{MATERIALS AND METHODS}

Based on the geographical specifications of the region, the sampling stations were identified at the north, south, east, west and center of the Ghaleh Kash region (Amol township) (Fig. 1) (Tavakol, 2007).

\section{Calculation of the sample size}

The sample size was calculated by the $n=(\delta / \delta / 3)^{2}$ formula with a certainty of $95 \%$ and the accuracy of 1.6 standard deviation. Before the spraying phase, samples were taken from all the selected stations in order to ensure that the water is free of OP insecticide.

In order to water sampling, 20 samples of one-L Volume 10 to $15 \mathrm{~cm}$ were collected. The collected samples were mixed together in a $20 \mathrm{~L}$ container. Eventually, from each station, 5 one L samples were collected. To prevent the decomposition of diazinon present in the water samples, $50 \mathrm{CC}$ methylene chloride solution was added to each sample between the sampling and laboratory phases (Tavakol, 2007).

Then, the samples were kept in refrigerators and sent to the pesticides chemical laboratory of the Health College of the Tehran Medical Sciences University. (Tavakol, 2007).

The sampling from all the stations were taken at least 5 times with the intervals time of one day, one week, two weeks, one month and two months .This was done after spraying for at least two months at the end of spring and summer of 2007 from June. This exactly coincided with the commencement of the spraying season (spraying was conducted from the June $4^{\text {th }}$ to $9^{\text {th }}$ ) it continued until mid August, when the residues of the insecticides were not detectable in the water. The number of samples was 125 and the recovery of insecticide and the partition of the organic phase from the liquid phase were performed according to the traditional methods, utilizing acetone and methylene chloride solvents and the decantation funnel (Sherma et al., 2005).
After the partition and recovery of diazinon insecticide from the water samples, the additional materials were taken out through the partition funnel and the desired insecticide was recovered by So4Na2. The clean up of the solution was performed in columns of silica gel. Then, the solution was concentrated by the rotary evaporation apparatus. The produced solutions were labeled as the unknown samples and in the next phase, their level of insecticide content was determined. (Futagami et al., 1997; Sherma et al., 2005)

In order to identify the recovery efficiency, a practical method was used. In another word, a specific amount of diazinon insecticide was added to the samples taken from the irrigation water known to be free of phosphorous pesticides. Then, through the method used in this study, diazinon was partitioned again from the water sample and was cleaned up and examined. Eventually, the amount of diazinon determined from this method was compared to the initial level and it was considered as the recovery efficiency. The amount of diazinon residue was determined by the (highperformance thin layer chromatography) HPTLC technique (Abbot, 1996; Futagami et al., 1997; Puglise et al., 2004; Sherman et al., 2005)

The diazinon standard of $10 \mathrm{mg}$ was acquired from the Accustandard Company of Switzerland. Utilization of the applicator and capillary 5, the spotting process was conducted on the aluminum plate, containing the silica-gel. This is considered as the stationary phase in this technique, where the standard solution and the prepared solutions from the water samples were used. For the spotting of the standard sample, the multiple level method was applied. In this method, several concentrations are used for the spotting of the standard sample (Futagami et al., 1997; Denistrop, 2000)

Subsequent to the spotting and drying processes, the prepared plate was placed inside a solvent tank for growth and development. The organic solvent was used as the mobile phase for the growth of the diazinon spots. This solvent was comprised of acetone-hexane mixture with the ratio of $80 \%$ to $20 \%$. It was poured into the tank and after the saturation of the tank (in about $30 \mathrm{~min}$ ) the prepared plate was placed inside it (Sherma, 2000; Sherma et al., 2005).

A period of $20 \mathrm{~min}$ was adequate for the growth of spots and the rise of the solvent (the required interval time depends on the size of the plate and the type of solvents inside the tank). Afterwards, the plate was taken out of the tank and dried. Then, the spots were 
examined inside a (ultra violet) UV cabinet with florescent light at the wavelength of $254 \mathrm{~nm}$. The diazinon $\mathrm{Rf}$ level was determined to be about $58 \%$ $(+/-2 \%)$. $\mathrm{Rf}$ is the distance traveled by the solvent (from the spotting point to the end) over the distance travelled by the pesticide (from the spotting point to the development point) $=$ Spot front /solvent front. Eventually, the (thin layer chromatography) TLC Scanner 3 and the CATS 4 software were utilized to scan the diazinon spots (Denistrop, 2000). For scanning the plate, the deuterium light at the wavelength of $257 \mathrm{~nm}$ was selected (Ahmad, 2001). At the conclusion, the amounts of diazinon present in each spot were directly determined by the CATS 4 software. The level of diazinon in unit volume of water was calculated from the amounts contained in each spot. At the end, the variation analysis and the (analysis of variance) ANOVA test were used in the data analysis (Tavakol, 2007).

\section{RESULTS AND DISCUSSION}

On 125 samples was conducted to assess the diazinon residues in various phases of the rice cultivation from the day after the spraying of the diazinon insecticide until when no trace of the insecticide was detectible in the studied rice paddies of Amol township. As it is shown in Table 1, the highest level of diazinon was detected the day after the spraying of station 1 in amount of $1.14 \mathrm{ppm}$. Generally, in the other stations, the amounts of pesticides were lower than the standard acceptable levels. The mean level of diazinon residue a day after the spraying in station 1 was $1.1391 \mathrm{ppm}$. Respectively, the mean levels in a week and two weeks after the spraying were $0.6636 \mathrm{ppm}$ and $0.048 \mathrm{ppm}$. In the mentiond station, the amount of diazinon was not measurable after one and two months. The mean levels of diazinon in station 2 a day, a week, two weeks and one month after spraying were 0.5281 ppm, $0.2551 \mathrm{ppm}, 0.092 \mathrm{ppm}$ and $0.021 \mathrm{ppm}$, respectively. There was no trace of diazinon, two months after the spraying. The mean levels of diazinon in station 3 a day, a week, two weeks and one month after spraying were $0.3058 \mathrm{ppm}, 0.1604 \mathrm{ppm}, 0.086 \mathrm{ppm}$ and $0.014 \mathrm{ppm}$, respectively. There was no trace of diazinon, two months after the spraying. The mean levels of diazinon in station 4 a day, a week and two weeks after spraying were $0.6174 \mathrm{ppm}, 0.1873 \mathrm{ppm}$ and $0.065 \mathrm{ppm}$, respectively. There was no trace of diazinon, one month and two months after the spraying. The mean levels of diazinon in station 5, a day, a week, two weeks, one month and two months after spraying were $0.9273 \mathrm{ppm}, 0.2823 \mathrm{ppm}, 0.1163 \mathrm{ppm}, 0.0521 \mathrm{ppm}$ and $0.001 \mathrm{ppm}$, respectively (Tavakol, 2007).

Based on the Table 1, the correlation between the diazinon residues in the sampling stations was preformed by the ANOVA test and was compared with the World Health Organization (WHO) standards (Table 2). No meaningful difference was observed (P $>$ $0.05)$. This is quite reasonable by the similarity of the climatic conditions in the studied areas and similar physiochemical characteristics in their irrigation waters (Fig. 2). The relationship between the time of irrigation and the levels of diazinon residues was also conducted by the ANOVA test (Table 3) The comparison of the various intervals time showed a meaningful difference $(\mathrm{P}<0.05)$. It indicates that time is an influential factor in the sampling process and as the time passes by, the amount of pesticide residues decreases (Fig. 3) (Shayeghi et al., 2001; Honarpajouh, 2003; Bagheri, 2007).

The amounts of diazinon in the stations 2 and 3, as well as the station 5 were detectable until the first and second month after the spraying phase, respectively. This is probably due to the insecticide's high

Table 1: Average results of the diazinon analysis in the rice paddies from each sampling station in 2007

\begin{tabular}{|c|c|c|c|c|c|c|}
\hline  & Time & $10-6-2007$ & $17-6-2007$ & $24-6-2007$ & $11-7-2007$ & $11-8-2007$ \\
\hline \multicolumn{7}{|l|}{ Station } \\
\hline 1 & & 1.1391 & 0.6637 & 0.048 & $\mathrm{~N}$ & $\mathrm{~N}$ \\
\hline 2 & & 0.5281 & 0.2551 & 0.092 & 0.021 & $\mathrm{~N}$ \\
\hline 3 & & 0.3058 & 0.1604 & 0.086 & 0.014 & $\mathrm{~N}$ \\
\hline 4 & & 0.6174 & 0.1873 & 0.065 & $\mathrm{~N}$ & $\mathrm{~N}$ \\
\hline 5 & & 0.9273 & 0.2823 & 0.1163 & 0.0521 & 0.001 \\
\hline
\end{tabular}

N: NOAEL: No-observed adverse effect level (Tavakol, 2007) 


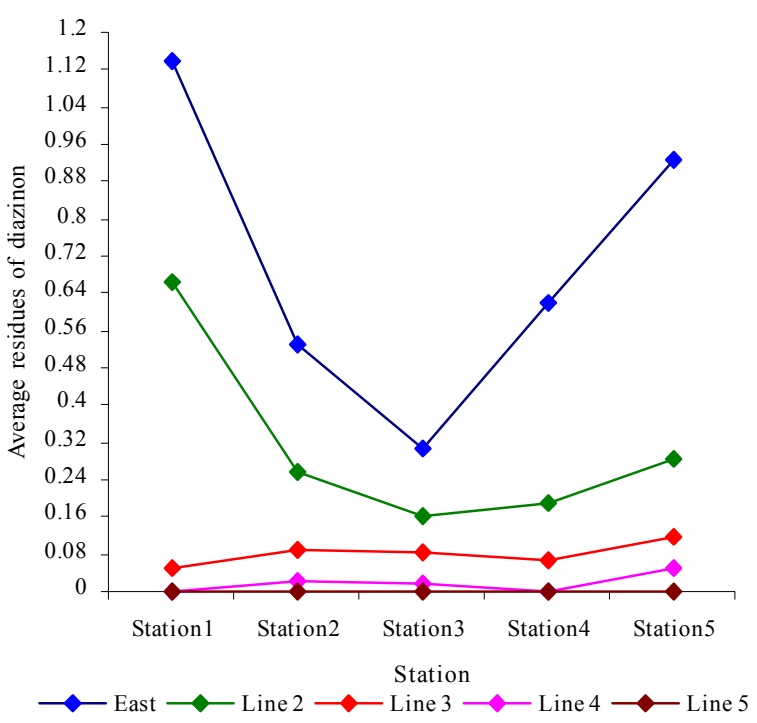

Fig. 2 : The average residues of diazinon in the waters of the rice paddies (Stations 1, 2, 3, 4 and 5)(Tavakol, 2007)

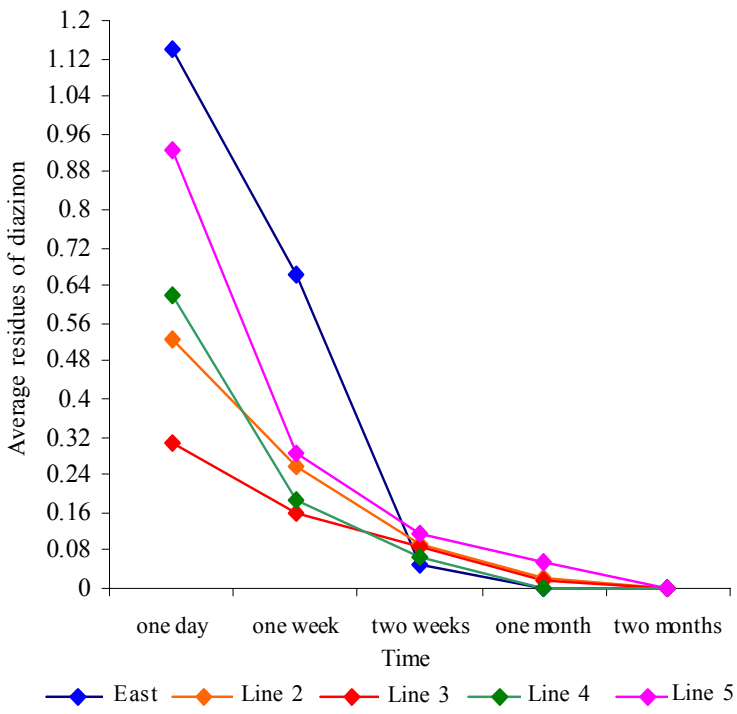

Fig. 3: The comparison of average residues of diazinon in various times (ppm)(Tavakol, 2007)

Table 2: ANOVA statistical analysis based on the sampling stations

\begin{tabular}{lccccc}
\hline & Sum of squares & $\mathrm{df}$ & Mean square & F & Sig. \\
\hline Between groups & 0.204 & 4 & 0.051 & 0.473 & 0.755 \\
Within groups & 2.155 & 20 & 0.108 & & \\
Total & 2.359 & 24 & & & \\
\hline
\end{tabular}

Table 3: ANOVA statistical analysis based on sampling time

\begin{tabular}{|c|c|c|c|c|c|c|}
\hline & & Sum of squares & $\mathrm{df}$ & Mean square & $\mathrm{F}$ & Sig \\
\hline Between groups & & 1.752 & 4 & 0.438 & 14.429 & 0.0 \\
\hline Within groups & & 0.607 & 20 & 0.03 & & \\
\hline Total & & 2.359 & 24 & & & \\
\hline \multirow[t]{2}{*}{ Time } & \multirow[t]{2}{*}{$\mathrm{N}$} & & \multirow{2}{*}{\multicolumn{2}{|c|}{ Subset for alpha $=.05$}} & & \\
\hline & & & & & & 3 \\
\hline $86 / 5 / 20$ & 5 & & 0.0002 & - & & - \\
\hline $86 / 4 / 20$ & 5 & & 0.01742 & - & & - \\
\hline $86 / 4 / 03$ & 5 & & 0.08146 & 0.08146 & & - \\
\hline $86 / 3 / 27$ & 5 & & - & 0.30976 & & - \\
\hline $86 / 3 / 20$ & 5 & & - & - & & 0.70354 \\
\hline Sig. & - & & 0.495 & 0.051 & & 1.0 \\
\hline
\end{tabular}

Means for groups in homogeneous subsets are displayed. Uses harmonic mean sample size $=5.000$ (Tavakol, 2007) 
persistency in the ambient environment. Moreover, the latest worldwide researches indicate that some OP pesticides like diazinon are more persistent than others (Struger, 2002; Sudo et al., 2002; Bondarenko et al., 2004).

The objective of the study conducted by the Water Quality Control Center in Sanjunquin River, California on aquatic contamination from 1990 to 1998 was to investigate the acute and chronic contamination of the living organisms in this river as the result of incoming pesticides. The aquatic contamination was linked to diazinon, chloriperinus and medidatiun. The pertinent department overseeing the consumption of pesticides in California studied one of the branches of this river in winter seasons during 1991-1993 period. It also detected $10 \%, 72 \%$ and 18 of chloriperinus, diazinon and medidatiun in 108 collected samples, respectively. Meanwhile, the diazinon concentration of $1.07 \mathrm{mg} / \mathrm{L}$ was observed, which indicated a chronic and potentially dangerous contamination of diazinon.

In order to determine the impact of pesticides on reproductive organs of fish species, Dutta et al. (2003) introduced diazinon to the testicles of Lepomis marchirury. The histopathology analysis of the testicles reveals changes in the cell mass due to the influence of the insecticide (Dutta et al., 2003).

The studies, conducted during 1991 to 1995 in the United States, point out that the levels of diazinon and methamidophos in the White River basin in the State of Indiana and 20 adjacent rivers are the highest in the analyzed samples. Also, it was observed that the residues of OP pesticides decrease as the samples are taken farther away from the sprayed region (Hamilton et al., 2003). In the present study, a declining trend in the insecticides was detected from the first day after the spraying until two months later. Other researches, performed in various regions of the Mazandaran province show that the rivers like Tajan, Safaa Roud and Babol Roud Rivers are contaminated with OP pesticides like azinphos methyl, malathion and diazinon. The amounts of these chemicals were higher than the allowable limits even 3 to 4 months after the spraying (Shayeghi et al., 2001)

The local residents of the sprayed regions are the most susceptible to the acute effects of the insecticides on the water resources and the general environment. However, their long term adverse consequences threaten regions away from the sprayed centers (Phillips and Bode, 2004; Abdel-Halim et al., 2006; Obendore et al., 2006). Currently in Iran, there are no appropriate standards for water and food products. Thus, the only available mean's to compare the results with the international standards (Tavakol, 2007).

According to the studies conducted by Shayeghi (2001) (rice fields and citrus orchards in Tonekabon), 6KD HJ KL (2004) (Mazandaran Province) and Honarpajouh (2001) (Seymineh River and its adjacent rivers), the traces of insecticides were detected 5, 4 and 3 months after the spraying, respectively. Furthermore, the present study discovered the residues, 2 to 3 months after the spraying.

' iazinon levels $\llbracket R$ up to 454 ppm $\square Z$ HHIP HDXUGWlin the Karaj Catchments Basin at the beginning of the pesticide spraying season. Meanwhile, Shayeghi et al. (2005) studied the residues of OP insecticides in Kor and Seyvand Rivers as well as the cucumber crops at the downstream of the above-mentioned rivers. In his study, he detected residues of diazinon in these rivers, especially $3.5 \mathrm{ppm}$ of diazinon in Seyvand River. Another research was conducted by Bagheri (2007) on the residues of OP insecticides in the fish species and the waters of Gharehsu and Gorganroud Rivers in Golestan Province, Iran. The highest and lowest levels of Diazinon were detected in summer (56 ppm) and winter, respectively. It was concluded that the insecticide residues depend on the physiochemical characteristics of water, time of consumption, $\mathrm{pH}$ of water and the ambient temperature (Bagheri, 2007).

The results of the above-mentioned researches confirm the findings of our study, based on the measured levels of poisonous materials. The findings reveal that the $\mathrm{pH}$, ambient temperature, slope of the farm land, precipitation, etc., have an influential impact on the persistence of diazinon in the farms of Amol (Tavakol, 2007). Therefore, it is essential to seriously consider the integrated pest management, supervision of pesticides' distribution and consumption (Krol et al., 2000), use of pesticides with low potential to contaminate the water and soil, conducting public awareness campaigns for the consumers ( $\mathrm{Na}$ et al., 2006) utilization of other pest control measures like parasitoids and biological methods instead of chemical remedies and finally, development of standards and identification of maximum residue limit (MRL) of the pesticides in the agricultural crops in the country (Tavakol, 2007). 


\section{ACKNOWLEDGEMENTS}

The authors wish to thank Tehran University of Medical Science for The financial support and express special gratitude to Dr. Shayeghi due to her cooperation in analyzing the samples.

\section{REFERENCES}

Abbot, D. C., (1996). The application of Thin layer chromatography technique to analysis residue. Reviwe. 2, 638-644 (7 pages)

Abdel-Ghani, N. T.; Hefny, M.; El-Chaghaby, G. A. F., (2007). Removal of lead from aqueous solution using low cost abundantly available adsorbents. Int. J. Environ. Sci. Tech., 4 (1), 67-74 (8 pages).

Abdel- Halim, K. Y.; Salama, A. K.; El-Khateeb, E. N.; Bakry, N. M., (2006). OP pollutants (OPP) in aquatic environment at Damietta Governorate, Egypt: Implications for monitoring and biomarker responses. Chemosphere, 63 (9), 1491-1498 (8 pages).

Ahmad, F. E., (2001). Analyses of pesticides and their metaboLes in foods and drinks. Trac-Trend. Anal. Chem., 20 (11), 649-661 (13 pages)

Bagheri, F., (2007). Study of pesticide residues (Diazinon, Azinphosmethyl) in the rivers of Golestan province (GorganRoud and Gharehsou), M.Sc. Thesis, Tehran University of Medical Science. Tehran, Iran.

Bondarenko, S.; Gan, J.; Haver, D. L.; Kabashima, J. N., (2004). Persistence of selected organophosphate and carbamate insecticides in waters from a coastal watershed. Environ. Toxicol. Chem., 23 (11), 2649-2654 (6 pages).

Chimwanza, B.; Mamba, P. P.; Moyo, B. H. Z.; Kadewa, W., (2006). The impact of farming on river banks on water quality of The rivers. Int. J. Environ. Sci. Tech. 2 (4), 353358 (6 pages).

Ckamaca, H., (2002). Alga growth inhibition by water pollution. Environ. Pollut., 117 (3) 411-419 (9 pages).

Cox, C., (1993). Diazinon fact sheet. J. Pestic. Reform., 3, 30-35 (6 pages)

Darko, G.; Acquaah, S. O., (2007). Levels of organo chlorine pesticides residues in meat. Int. J. Environ. Sci. Tech., 4 (4), $521-524$ (4 pages).

Denistrop, H. E., (2000). Applied thin layer chromatography: best practice and avoidance of mistakes. Published by WileyVch. 1-304.

Dutta, H. M; Mejer, H. J. M.,(2003). Sublethal effect of diazinon on the structure of the thesis of blue gill lepomis macroscopic analysis. Environ. Pollut., 125 (3), 355-360 (6 pages).

Erin, M.; Hertz-Picciotto, B. I.; James, J. B., (2001). Case cohort analysis of agricultural pesticide applications near maternal residence and selected causes of fetal death. Am. J. Epidemiol., 154 (8), $702-710$ (8 pages)

Futagami, K.; Narazaki, C.; Kataoka, Y.; Shuto, H.; Oishi, R., (1997). Application of high- performance thin- layer chromatography for the detection of organoOP insecticides in human serum after acute poisoning. J. Chromatogr. B., 704 (1-2), 369-373 (5 pages).

Hamilton, D. J.; Ambrus, A.; Dieterl, R. M.; Felsot, A. S.; Harris, C. A.; Holland, P. T.; Katayama, A.; Kurihara, N.;
Linders, J.; Unsworth, J.; S. S. Wong (2003). Regulatory limits for pesticide residues in water. (IUPAC Technical Report). International Union of Pure and Applied Chemistry. Pure Appl. Chem., 75 (8), 1123-1155 (33 pages).

Hela, D. G.; Lambropoulou, D. A.; Konstantinou, I. K.; Albains, T. A., (2005). Environmental monitoring and ecological risk assessment for pesticide contamination and effects in Lake Pamvotis, Northwestern Greece. Environ. Toxicol. Chem., 24 (6), 1548-1556 (9 pages).

Honarpajouh, K., (2003). Study and Identification of OP pesticides residues (Azinphosmethyl and Diazinon) in the Mahabad and Siminerood Rivers, M.Sc. Thesis, Tehran University of Medical Science. Tehran, Iran.

Imo, S. T.; Sheikh, M. A.; Hirosawa, E.; Domori, T.; Tamaki, F., (2007). Contamination by organochlorine pesticides from rivers. Int. J. Environ. Sci. Tech., 4 (1), 1-9 (9 pages)..

Krol, W. J.; Arsenult, T. L.; Pylypiw, H. M.; Incorvia Mattina, M. J., (2000). Reduction of pesticide residues on produce by rinsing. J. Agr. Food. Chem., 48 (10), 4666-4670 (5 pages).

Mahvi, A. H., (2008). Application of agricultural fibers in pollution removal from aqueous solution. Int. J. Environ. Sci. Tech., 5 (2), 275-285 (11 pages).

Mumin, M. A.; Khan, M. M. R.; Akhter, K. F.; Uddin, M. J., (2007). Potentiality of open burnt clay as an adsorbent for the removal of Congo red from aqueous solution. Int. J. Environ. Sci. Tech., 4 (4), 525-532 (8 pages).

Na, T.; Fang, Z.; Zhanqi, G.; Ming, Z.; Cheng, S., (2006). The status of pesticide residues in the drinking water sources in Meiliangwan bay. Taihu lake of China. Environ. Monitor. Assess., 123 (1-3), 351-370 (20 pages).

Nouri, J.; Arjmandi, R.; Bayat, H., (2000). Ecological investigation of application of pesticides in rice fields. Iran. J. Public Health, 29 (1-4), 137-146 (10 pages).

Obendore, F. S. K.; Lemley, A. T.; Hedage, A.; Kline, A. A.; Tank Dokuchanyeva, T., (2006). Distribution of pesticide residues within homes in central New York State. Arch. Environ. Con. Tox., 50 (1), 31-44 (13 pages).

Pedersen, J. A.; Yeager, M. A.; Suffet, I. H., (2006). OP insecticides in agricultural and residential runoff: Field observations and implications for total maximum daily load development. Environ. Sci. Tech., 40 (7), 2120-2127 (8 pages).

Phillips, P. J.; Bode, R. W., (2004). Pesticides in surface water runoff in south-eastern New York state,US seasonal and storm flow effects on concentration. Pest Manage. Sci., 60 (6), 531-543 (12 pages ).

Puglise, P.; Molto, J. C.; Damiani, P.; Marin, R.; Cossignani, L.; Manes, J., (2004). Gas Chromatographic evaluation of pesticide residue contents in nectarines after non-toxic washing treatments. J. Chromatogr. A., 105 (2), 185-191 (7 pages).

Rawn, D. f.; Quade, S. C.; Shield, J. B.; Conca, G.; Sun, W. F.; Lacroix, G. M., (2006) Organophosphate levels in apple composites and individual apples from a treated Canadian orchard. J. Agric Food Chem., 54 (5), 1943-1948 (6 pages).

Shayeghi, M., Shahtaheri, S. J., Selseleh, M., (2001). Phosphorous insecticides residues in Mazandaran River Waters, Iran, Iran. J. Public Health, 30 (1), 115-118 (4 pages).

Sherma, J., (2000). Pesticide residuc analysis 1999-2000: A review. Lafayette College, Department of Chemistry, Easton, 
PA 18042, USA. J. AOAC Int. 2001; 84 (5), 1303-1312 (10 pages).

Sherma, J.; Larkin, J. D.; Larkin, F. H., (2005). Thin - layer Chromatography densitometers: an update. Lafayette College, Department of Chemistry, USA, J. AOAC Int., 88 (4), 85A-91A (7 pages).

Struger, J., (2002). Pesticide concentration in the Don and number river watersheds 1998-2000. Environment Canada. $1-3$

Sudo, M., Kunimatsu, T., Okubo, T., (2002). Concentration and loading of pesticide residues in lake Biwa Basin (Japan). Water Res., 36 (1), 315-325 (11 pages).
Tarahi Tabrizi, S., (2001). Study of pesticide residues (diazinon, malathion, metasytoux) in the Tabriz Nahand River. M.Sc. Thesis, Tehran University of Medical Science, Tehran, Iran. Tavakol, M., (2007). Environmental impact assessment of diazinon in rice fields (a Case Study on Amol Township Rice Fields), M.Sc. Thesis, Science and Research Branch, Islamic Azad University, Tehran, Iran.

Wilsont, P. C., Foos, J. F., (2006). Survey of carbamate and organophosphorous pesticide export from a south Florida (USA) agricultural watershed: Implications of sampling frequency on ecological risk estimation. Environ. Toxicol. Chem., 25 (11), 2847-2852 (6 pages).

AUTHOR (S) BIOSKETCHES

Arjmandi, R., Ph.D., Assistant Professor, Department of Environmental Management, Graduate School of the Environment and Energy, Science and Research Branch, Islamic Azad University, Tehran, Iran. Email: rezaarjmandi@yahoo.com

Tavakol, M., M.Sc., Department of Environmental Management, Graduate School of the Environment and Energy, Science and Research Branch, Islamic Azad University, Tehran, Iran. Email: mitra_tavakol@yahoo.com

Shayeghi, M., PhD., Associate Professor, Department of Medical Entomology, School of Public Health and Institute of Health Center, Tehran University of Medical Science, Tehran, Iran. Email: mansoreshayeghi@yahoo.com

How to cite this article: (Harvard style)

Arjmandi, R.; Tavakol. M.; Shayeghi, M., (2010). Determination of organophosphorus insecticide residues in the rice paddies. Int. J. Environ. Sci. Tech., 7 (1), 175-182. 